\title{
Construindo o Gênero na Escola: Ações Visíveis e Invisíveis
}

\author{
Construyendo el Género en la Escuela: Acciones Visibles e Invisibles
}

\author{
Building Gender in School: Visible and Invisible Actions
}

\author{
Íngrid Schmidt Visentini ${ }^{1}$ \\ Lidiane Londero Perlin² \\ Denise Silva Nunes ${ }^{3}$ \\ Letícia Machado Spinelli ${ }^{4}$
}

\begin{abstract}
Resumo
O presente estudo busca analisar os papéis de gênero no ambiente escolar, observando a construção de gênero em uma dicotomia entre feminino e masculino e de que forma isso se dá a partir das ações das crianças e do professor/professora com a respectiva influência ou não de fatores tanto internos quanto externos ao ambiente escolar. Observa-se que meninos e meninas são dissociados conforme seus gêneros. As crianças apreendem e reproduzem que há uma separação entre os gêneros feminino e masculino e esse aprendizado é construído a partir de questões aparentemente simples, tais como: o banheiro o qual devem frequentar, as roupas as quais devem usar, as cores designadas como adequadas e os tipos de brinquedos que devem brincar. Na educação infantil, essa distinção também está presente e acontece desde o formar a fila dos meninos e a fila das meninas. Além dessas ações visíveis bem direcionadas, as próprias crianças, em momentos nos quais não há a imposição de papéis de gênero, tendem a reproduzir a dicotomia do masculino e do feminino como quem adota e adere ao papel social que lhe é atribuído. Tendo em vista esta perspectiva de estrutura e agência na qual se conjugam ações visíveis e invisíveis, buscamos analisar a vigorosa lógica dicotômica que "compartimenta" meninas e meninos no contexto da vida escolar.
\end{abstract}

Palavras-Chave: Gênero. Educação. Papéis de gênero.

\section{Resumen}

El presente estudio busca analizar los roles de género en el ambiente escolar, observando la construcción de género en una dicotomía entre femenino y masculino y de qué forma se da a partir de las acciones de los niños y del profesor / profesora con la respectiva influencia o no de factores tanto internos como externos al ambiente escolar. Se observa que los niños y las niñas son disociados según sus géneros. Los niños incautan y reproducen que hay una separación entre los géneros femenino y masculino y ese aprendizaje se construye a partir de cuestiones aparentemente simples, tales como: el cuarto de baño el cual deben frecuentar, las ropas que deben usar, los colores designados como adecuados y los tipos de juguetes que deben jugar. En la educación infantil, esta distinción también está presente y ocurre desde formar la fila de los niños y la fila de las niñas. Además de estas acciones visibles bien dirigidas, los propios niños, en momentos en que no hay la imposición de papeles de género, tienden a reproducir la dicotomía de lo masculino y lo femenino como quien adopta y adhiere al papel social que le es atribuido. En vista de esta perspectiva de estructura y agencia en la que se conjugan acciones

\footnotetext{
${ }^{1}$ Estudante de Ciências Sociais (Bacharelado) na Universidade Federal de Santa Maria; Departamento de Ciências Sociais; Santa Maria, Rio Grande do Sul, Brasil; ingridvisentini@hotmail.com

${ }^{2}$ Estudante de Pedagogia na Universidade Federal de Santa Maria; Centro de Educação; Santa Maria, Rio Grande do Sul, Brasil; lidiane.londero@ @otmail.com

${ }^{3}$ Estudante de Ciências Sociais (Bacharelado) na Universidade Federal de Santa Maria; Departamento de Ciências Sociais; Santa Maria, Rio Grande do Sul, Brasil; denise.silva.nunes@ gmail.com

${ }^{4}$ Doutora em Filosofia; Professora temporária na modalidade PNPD/CAPES do Departamento de Ciências Sociais da Universidade Federal de Santa Maria; Santa Maria, Rio Grande do Sul, Brasil; leticiamspinelli@gmail.com
} 
visibles e invisibles, buscamos analizar la vigorosa lógica dicotómica que "comparte" a niñas y niños en el contexto de la vida escolar.

Palabras claves: Género. Educación. Papeles de género.

\begin{abstract}
The present study seeks to analyze the gender roles in the school environment, observing the construction of gender in a dichotomy between feminine and masculine and how it is based on the actions of the children and the teacher with the respective influence or not of factors both internal and external to the school environment. It is observed that boys and girls are dissociated according to their genders. The children learn and reproduce that there is a separation between the feminine and masculine genders, and this learning is constructed from seemingly simple questions, such as: the bathroom which they must attend, the clothes they must wear, the colors designated as adequate and the types of toys they should play. In early childhood education, this distinction is also present and occurs from the queue of the boys and the queue of the girls. In addition to these well-directed visible actions, children themselves, at a times when there is no genders roles imposition, tend to reproduce the male and female dichotomy as who adopting and adhering to the social role assigned to them. In view of this perspective of structure and agency in which visible and invisible actions are combined, we seek to analyze the vigorous dichotomous logic that "compartment" girls and boys in the context of school life.
\end{abstract}

Keywords: Genre. Education. Gender roles.

\title{
1. Introdução
}

As mensagens de formação e informação de estereótipos de gênero estão distribuídas nos mais variados espaços, contudo, é ponto de acordo que a escola constitui o ambiente que mais fortemente impacta nesse ponto de vista, quer pelo tempo que se passa nesse domínio, quer pela descoberta de relações que ela introduz ou, ainda, pela (cada vez mais) precoce idade em que se passa a frequentar esse ambiente. A investigação que aqui nos ocupamos não pretende converter os educadores em os únicos responsáveis pela formação e propagação dos estereótipos de gênero, tampouco demonizar o ambiente escolar nos termos de um domínio de treinamento de como se deve agir a partir do marcador de gênero. $\mathrm{O}$ que procuramos, mais precisamente, é apresentar como o ambiente escolar influencia na manutenção e propagação de estereótipos de gênero perante práticas adotadas na organização e socialização do educando, ou seja, mediante ações visíveis, e, como, ainda, o ambiente escolar se constitui em palco no qual os indivíduos manifestam (sem práticas escolares visíveis que os condicionam) a adesão a comportamentos de acordo com o seu gênero. Dentro dessa dicotomia de, por um lado, certo aprendizado de gênero e, por outro, certa adesão a um padrão de gênero, se insere a própria díade de estrutura e agência. O que pretendemos, enfim, trazer, é que a escola constitui um espaço de ações visíveis na propagação de comportamentos generificados segundo a sua configuração estrutural, mas, também, em espaço no qual os indivíduos, mediante ações invisíveis (não provocadas diretamente pela práxis escolar) aderem- segundo certa espontaneidade - a essa configuração. 
Diante desse intento, o texto que segue se estrutura nos seguintes termos: inicialmente, apresentar as questões básicas que compõem o repertório teórico-conceitual das questões relativas ao gênero, especialmente no que tange à formação de estereótipos; em seguida, apresentar a estrutura que compõem as diretrizes da educação bem como (esse é o ponto central da nossa análise) como são tradicionalmente organizadas as atividades escolares (nos primeiros anos de ensino) que interferem ou tocam a questão de gênero e como, independentemente delas, se manifesta (quando as indicações não estão presentes) certa autonomia dos educandos em prorrogar e aderir às divisões de gênero. Por fim, é abordado a questão dos limites e possibilidades do modelo de socialização, buscando trazer que estrutura e agência não são modelos de reflexão que se pode tomar como hegemônicos. Sozinhos e de modo excludente podem se manter coerentes teoricamente, mas não abarcam de maneira clara a complexidade da vivência em sentido amplo e da vivência escolar em sentido particular.

\section{Gênero e estereótipos de gênero}

Foi junto à Psicologia, particularmente na metade do século XX, que o termo gênero passou a ser utilizado com o significado diferente do puramente gramatical. O psicólogo Robert Stoller apontou, nos seus estudos psicanalíticos aplicados à transsexualidade, a importância de levar em consideração as influências e direcionamentos que as designações socioculturais têm na identidade pessoal e no comportamento de homens e mulheres. Assim designou "gênero" como uma ferramenta teórica no sentido de distinguir o corpo com suas características biológicas e a identidade construída sob os efeitos das influências socioculturais.

Foi no final dos anos 70, no domínio da chamada segunda onda do feminismo, que a teoria feminista passa adotar conceito de gênero enquanto construção social como categoria central de análise. Obviamente que isso não se deu espontaneamente, sem uma preparação prévia. Sob esse aspecto, é interessante mencionar a obra O Segundo Sexo de Simone de Beauvoir que, entre outras contribuições, consolidou a análise de que ser homem e mulher pressupõe uma construção social e não é determinado biologicamente. Isso foi sintetizada na afamada passagem de Beauvoir (2009, p.09) "Ninguém nasce mulher: torna-se mulher". Beauvoir estava falando, de modo mais pontuado, da formação da feminilidade, em nossa investigação, porém, essa passagem é incorporada no sentido de dizer, igualmente, e obedecendo a paráfrase, que "ninguém nasce homem, torna-se homem". Isso é fundamental para deixar claro que modelos de masculinidades também obedecem aos usos e costumes socialmente fortificados e sob esse aspecto também atuam como inibidores e castradores para 
os homens. Forçoso, nesse sentido, é que só existem estereótipos femininos em razão de existirem os masculinos e vice-versa.

A incorporação da categoria gênero veio no sentido de teorizar que os comportamentos de homens e mulheres obedecem a um princípio organizacional da sociedade. Sob esse aspecto, juntamente com a categoria gênero, juntam-se noções referentes a estereótipo, status e papéis. Assim, conforme Scott, gênero é

\begin{abstract}
utilizado para designar as relações sociais entre os sexos. O seu uso rejeita explicitamente as justificativas biológicas, como aquelas que encontram um denominador comum para várias formas de subordinação no fato de que as mulheres tem filhos e que os homens tem uma força muscular superior. O gênero se torna, aliás, uma maneira de indicar as "construções sociais" - a criação inteiramente social das ideias sobre os papéis próprios aos homens e às mulheres. É uma maneira de se referir às origens exclusivamente sociais das identidades subjetivas dos homens e das mulheres. O gênero é, segundo essa definição, uma categoria social imposta sobre um corpo sexuado (SCOTT, 1991, p.7)
\end{abstract}

A dominante e disseminada dicotomia de gênero coloca homens e mulheres em dois lados opostos. O exemplo do porta-casacos da identidade de Nicholson (2000) ilustra a relação entre biologia e socialização, ou seja, entre o corpo que é visto e as designações (não vistas) postas sobre ele: o corpo é visto como um tipo de cabide de pé no qual são jogados diferentes artefatos culturais, especificadamente os relativos a personalidade e comportamento. Assim, quando se pensa o corpo como um "cabide" no qual são "jogados" certos aspectos de personalidade e comportamento, pode-se pensar no relacionamento entre os dados do "cabide" e aquilo que nele é jogado como algo mais fraco que determinista, porém mais forte do que acidental. Não se é obrigado a jogar sobretudos e cachecóis num portacasacos; pode-se, por exemplo, jogar suéteres e até diferentes tipos de objetos, basta mudar suficientemente a natureza material do cabide. Mas se sempre vemos um porta-casacos cheio de sobretudos e cachecóis, não exigimos muita explicação, afinal trata-se de um porta-casacos (NICHOLSON, 2000, p.4).

O porta-casacos refere-se a como as pessoas são cobradas nos termos de suas "categorias sexuais" presumidas como homem ou mulher. Fazemos nosso próprio gênero, mas não somos livres para o fazermos como quisermos. Nossa prática de gênero é poderosamente formatada pela ordem de gênero em que nos encontramos (CONNEL; PEARSE, 2015, p.156). A questão do estereótipo aqui é fundamental. Os estereótipos de gênero correspondem a moldes de ser e agir a partir dos quais homens e mulheres são compartimentados, distintos entre homens e mulheres e homogeneizados dentro do próprio gênero. $\mathrm{O}$ indivíduo é moldado segundo seu gênero, e esse molde é delineado por reforços exteriores positivos ou negativos que contribuem para um comportamento apropriado 
segundo seu gênero. Os estereótipos são transmitidos e propagados nos costumes, mídia, religião, unidade familiar, entre outros setores. Enquanto homens devem se enquadrar em um estereótipo que contempla características como ser ativo, forte, alto, robusto, vigoroso, gostar de esportes, as mulheres devem se enquadrar em um estereótipo oposto: passivas, delicadas, gostam de ler/estudar, românticas, carinhosas.

Assim, "ser homem" ou "ser mulher" está relacionado a ser um conjunto de características determinadas, que vão sendo adquiridas, construídas e vivenciadas por cada pessoa. Isso se faz desde antes o nascer, quando se descobre o sexo ainda durante a gestação. A partir daí elementos socialmente construídos como determinantes de gênero vão sendo agregados na constituição do indivíduo. Está pré-determinado qual cor a criança vai usar e de que modo irá agir. Os bebês identificados como meninas ou meninos são colocados em roupas cor-de-rosa ou azuis, respectivamente. Dos bebês de azul, espera-se que se comportem de maneira mais severa e bruta e que sejam mais exigentes e vigorosos. No momento "certo", vão receber armas de brinquedo, bolas de futebol e jogos de computador. Dos bebês cor-derosa, espera-se que sejam mais passivos, obedientes e mais bonitos. Conforme crescem, são colocados em roupas cheias de frufrus, ganham bonecas e kits de maquiagem, são ensinados a cuidar da aparência e a serem educados e agradáveis (CONNEL; PEARSE, 2015).

Nossos corpos constituem-se na referência que ancora, por força, a identidade. E, aparentemente, o corpo é inequívoco, evidente por si; em conseqüência, esperamos que o corpo dite a identidade, sem ambiguidades nem inconstância (LOURO, 2000, p.8).

É sempre esperado um padrão de como ser e agir de acordo com o nosso gênero, fugir desse padrão causa estranhamento e confusão. As sanções positivas levam a recompensas para quem age conforme as normas, como: sorrisos da mãe, aprovação dos amigos, sucesso no jogo de sedução, indicação para um bom emprego. A não conformidade ou o desvio levam a sanções negativas, que vai de olhares de reprovação a surras, ou a serem presos (CONNEL; PEARSE, 2015). Ser do sexo feminino, ou, ser do sexo masculino e não aparentar visualmente produz um estranhamento, uma incerteza, isso porque a indeterminação visual corpo/gênero não reflete à primeira vista a identidade. A concepção de que o nosso corpo reflete a nossa identidade está disseminada, estando muito atrelada à questão biológica. Há uma dicotomia em como se percebe o gênero e como ele é construído e vivenciado a partir dessa dualidade:

A maioria das discussões sobre gênero na sociedade enfatiza uma dicotomia. Ao começar a partir de uma divisão biológica entre homens e mulheres, define-se gênero como diferenças sociais ou psicológicas que correspondem a essa divisão, sendo construídas sobre ela ou causadas por ela. Em seu uso mais comum, então, o 
termo "gênero" significa a diferença cultural entre mulheres e homens, baseada na divisão entre fêmeas e machos. A dicotomia e a diferença são a substância dessa idéia. Os homens são de Marte e as mulheres são de Vênus (CONNEL; PEARSE, 2015, p.46)

Estereótipos são castradores uma vez que direcionam homens e mulheres independentemente de suas subjetividades, contudo, a força do estereótipo de gênero na apreciação social leva os sujeitos a aderirem (em maior ou menor grau) aos padrões de seu gênero.

Os medos que são portadores homens e mulheres colaboram grandemente para que cada um observe a receita de como ser homem e mulher. Os homens temem ser considerados menos machos se forem flexíveis, pacíficos e generosos. As mulheres temem ser tomadas como pouco femininas incapazes de conservar o "amor" do companheiro, se se relevarem empreendedoras, dinâmicas, bem-sucedidas (SAFFIOTI, 1987, p.39).

Conforme as feminilidades e as masculinidades vão sendo construídas socialmente, as imposições dos padrões de gênero se consolidam majoritariamente de forma rígida, fazendo com que as pessoas que as aderem, as façam de forma extrema, usando de sanções negativas com as outras pessoas de mesmo gênero, e, muitas vezes, de maneira violenta. Segundo Saffioti (1987) o homem que não se tornar viril se aproxima de mulheres, isso porque a virilidade é a negação das características ditas femininas. O homem, também, é o chefe e provedor das necessidades da família, bem como um ser que descarrega suas tensões através do exercício sexual, mecanizando a prática sexual como alívio. Já a mulher, é socializada para o papel de vítima, colocada sempre em uma situação de inferioridade.

Essas feminilidades e masculinidades tóxicas impõem um padrão a ser seguido, moldando comportamentos e aparências, acarretando em uma castração do homem, que está na condição de virilidade; na castração da mulher, que está na condição de inferioridade; e ocasionando, também, a castração da família, onde a autoridade está nas mãos de quem educa, ou seja, o pai é a autoridade máxima, reproduzindo, assim, os papéis nos filhos e filhas. Assim, os padrões de gênero fazem com que determinados elementos sejam característicos para cada sexo, comportando-os em uma binaridade de gênero.

O gênero é uma das referências recorrentes pelas quais o poder político foi concebido, legitimado e criado. Ele se refere á oposição masculino/feminino e fundamenta ao mesmo tempo seu sentido. Para reivindicar o poder político, a referência tem que aparecer segura e fixa fora de qualquer construção humana, fazendo parte da ordem natural ou divina. Desta forma, a oposição binária e o processo social das relações de gênero tornam-se, os dois, parte do sentido do poder, ele mesmo. Colocar em questão ou mudar um aspecto ameaça o sistema por inteiro. (SCOTT, 1989, p. 27) 
A diferença sexual, em termos de controle das mulheres, é apenas um modo da organização das relações de poder. Esse tipo de dominação é constituída pela desigualdade de gênero, na qual o masculino e o feminino são compreendidos como algo natural, generalizando e reproduzindo seus significados na cultura como algo normativo. Trata-se de um processo político, em que se estabelecem as definições normativas de gênero a partir da relação contínua entre vários atores, ou seja, são padrões construídos reciprocamente entre homens e mulheres.

Essa aplicação de elementos, valores e comportamentos nos corpos se dá antes da concepção dos mesmos e se mantém de forma continuada ao longo do desenvolvimento humano. Esse investimento é a forma como construímos o gênero. Nós nos construímos para nos adequar a critérios que nos identifique como homem e como mulher. Não somente é esperado que homens e mulheres ajam de tal maneira ou pareçam de tal jeito, como também homens e mulheres, em sua maioria, agem e parecem segundo padrões de gênero já estabelecidos. Existe uma adesão em fazer com que nosso corpo reflita a nossa identidade, sendo a imagem física de quem somos.

\begin{abstract}
Assim, não podemos pensar o ser mulher ou o ser homem como experiências fixadas pela natureza. Mas também não podemos pensá-los apenas como uma imposição externa realizada por meio de normas sociais ou da pressão de autoridades. As pessoas constroem a si mesmas como masculinas ou femininas. Reivindicamos um lugar na ordem de gênero - ou respondemos ao lugar que nos é dado -, na maneira como nos conduzimos na vida cotidiana (CONNEL; PEARSE, 2015, p.39).
\end{abstract}

As masculinidades e feminilidades não são um estado predeterminado, mas sim uma condição ativamente em construção. Essa construção é desenvolvida por cada pessoa, a partir de sua própria identidade de gênero. A sensação de pertencimento a uma categoria de gênero é subjetiva a cada um e cada uma, incluindo significados particulares sobre esse pertencimento. Mesmo considerando todos os fatores que nos são apresentados estruturalmente, somos nós que vamos desenvolvendo e "escolhendo" aquilo que nos identifica. Muitas vezes aceitamos de vontade própria, outras vezes, é repressivo a nós e buscamos outra alternativa. Todavia, a maioria de nós combina características femininas e masculinas sem se concentrar especificadamente em um ou outro.

A adesão da agência à estrutura está relacionada a como nós nos submetemos a padrões que dão significado aos nossos corpos, sem ninguém “nos obrigar”. As opções são disseminadas e estão disponíveis a quem optar pelo uso. Participamos ou não porque fazemos parte do processo.

\title{
3. A escola e o "aprendizado" de gênero
}


A Educação Básica, a qual compreende a Educação Infantil, o Ensino Fundamental e o Ensino Médio escolar, tem o dever de promover as interações, as trocas de saberes e conhecimentos, disseminar as diferenças culturais, raciais, sexuais e de gênero. Isso é requerido no sentido de permitir que os educandos tenham conhecimentos sobre contextos que se divergem dos seus, fazendo com que os mesmos valorizem suas culturas e as culturas da população em geral, para assim formarem sua identidade e compreenderem aspectos básicos importantes para viver em harmonia com a sociedade. Enquanto espaço de formação e cidadania, cabe ao ambiente escolar promover igualdade de condições, o que pede por informação, liberdade e empatia. A questão de gênero é fundamental de ser debatida nesse contexto, uma vez que abarca questões acerca do comportamento convencionado para homens e mulheres (em que se põe em destaque papéis de gênero) e questões de sexualidade (a qual implica esfera do desejo e da identidade). Abordar essas questões junto ao cotidiano escolar repercute quer em igualdade e liberdade entre as diferentes orientações de comportamentos e sexualidade quer em um abrandamento da violência física e psicológica (convencionada como bullyng) no interior do ambiente escolar. Ademais, é inegável que o tratamento dessas questões repercute junto à sociedade em geral, paulatinamente, produz gerações mais conscientes e equilibradas.

\section{Conforme aborda as Diretrizes Curriculares Nacionais da Educação Básica}

A Base Comum Nacional junto as tecnologias de informação e comunicação perpassem transversalmente a proposta curricular desde a Educação Infantil até o Ensino Médio, imprimindo direção aos projetos político-pedagógicos.

Ambas possuem como referência geral o compromisso com saberes de dimensão planetária para que, ao cuidar e educar, seja possível à escola conseguir:

I - ampliar a compreensão sobre as relações entre o indivíduo, o trabalho, a sociedade e a espécie humana, seus limites e suas potencialidades, em outras palavras, sua identidade terrena;

II - adotar estratégias para que seja possível, ao longo da Educação Básica, desenvolver o letramento emocional, social e ecológico; o conhecimento científico pertinente aos diferentes tempos, espaços e sentidos; a compreensão do significado das ciências, das letras, das artes, do esporte e do lazer;

III - ensinar a compreender o que é ciência, qual a sua história e a quem ela se destina;

IV - viver situações práticas a partir das quais seja possível perceber que não há uma única visão de mundo, portanto, um fenômeno, um problema, uma experiência, podem ser descritos e analisados segundo diferentes perspectivas e correntes de pensamento, que variam no tempo, no espaço, na intencionalidade;

$\mathrm{V}$ - compreender os efeitos da "infoera", sabendo que estes atuam, cada vez mais, na vida das crianças, dos adolescentes e adultos, para que se reconheçam, de um lado, os estudantes, de outro, os profissionais da educação e a família, mas 
reconhecendo que os recursos midiáticos devem permear todas as atividades de aprendizagem (DCN, 2013, p. 33).

$\mathrm{Na}$ perspectiva das Diretrizes Curriculares Nacionais da Educação Básica é mencionado que "não há uma única visão de mundo", ou seja, não existe uma verdade absoluta que deva ser vista como única e correta. É a partir dessa frase que iremos desenvolver a questão de como o gênero é visto na escola, afim de apresentar um estudo que não se permeia em apenas um molde de como o gênero é visto, estudado e aprendido no âmbito escolar, trazendo assim, amplas visões sobre o ensino-aprendizagem de gênero na escola.

A questão de gênero perante a educação tradicional é vista e trabalhada com os educandos como a divisão de banheiros para meninos e meninas, a separação de brinquedos para meninos e para meninas, as brincadeiras de meninos e de meninas, ou seja, o gênero é visto apenas como algo material e como uma ação estabelecida pela comunidade escolar, onde certos objetos são separados em quais os meninos podem e devem usar e quais objetos as meninas podem e devem usar, assim como quais comportamentos são esperados e devem ser seguidos tanto pelos meninos quanto pelas meninas, onde o menino é visto como um educando bagunceiro e sem interesse pelos estudos e a menina é vista como a comportada e estudiosa e assim ambos devem ser, como observamos na citação a seguir:

As justificativas da diferença de desempenho expressam a percepção de que "os meninos são mais inteligentes, porém, indisciplinados; enquanto as meninas são atentas e aplicadas, mas menos inteligentes". Traçam, portanto, um perfil dos alunos e das alunas, delineando as características que enxergam e ressaltam. Ao mesmo tempo que percebem essas características ancorando-as nas suas próprias concepções e representações, vão também construindo contornos e assim dando forma aos próprios comportamentos de seus/suas alunos/as. Outras caracterizações dos comportamentos indicam "as meninas como mais responsáveis, dedicadas, estudiosas, interessadas, sensíveis, atentas". Enquanto "os meninos são malandros, não tem hábitos de estudo, não ficam em casa para estudar, saem para jogar bola, faltam às aulas, são dispersivos, têm interesses fora da escola, são agitados, não prestam atenção, ainda que mais inteligentes" (SILVA; BARROS; HALPERN; SILVA, 1999, p. 215).

Neste sentido, a visão da comunidade escolar tradicional, mais precisamente das professoras, as quais passam a maior parte do tempo com os educandos na escola, é altamente generificante, atribuindo aos meninos o título de indisciplinados e as meninas o título de disciplinadas, como se esse comportamento estivesse ligado ao gênero biológico do educando e não aos seus contextos, tempos e espaços. Atualmente a nova metodologia pedagógica alternativa quebra os paradigmas da metodologia tradicional e revela que cada educando é diferente entre si, sendo estes do mesmo gênero ou não. 
É necessário respeitar o tempo de maturação, de desenvolvimento das ferramentas do fazer e do entender, da emergência plena, lenta, extravagante, lúcida e em constante mudança das capacidades das crianças; essa é uma medida do bom senso cultural e biológico. Se a natureza que comanda todos os animais afirma que a infância deve durar mais nos seres humanos $|. .$.$| isso ocorre porque a natureza sabe$ quantos rios existem para serem cruzados e quantas trilhas precisam repisar. A natureza dá tempo para a correção dos erros (tanto pelas crianças, quanto pelos adultos), para a superação de preconceitos, e para que as crianças tomem fôlego e restaurem a sua auto imagem, a dos seus companheiros, dos seus pais, dos professores e do mundo (MALAGUZZI, 1999, p. 76).

Os Parâmetros Curriculares Nacionais (PCN's) trazem em seus temas transversais uma das áreas que abordam a orientação sexual, que se intercala entre - corpo: matriz da sexualidade, relações de gênero, prevenções das doenças sexualmente transmissíveis. Não é propriamente estabelecido pela legislação que se estude o que é gênero na escola, e sim englobe o assunto de gênero nas demais disciplinas, áreas e temas estudados. Como, por exemplo, no Ensino Médio ou no Ensino Fundamental, quando o educador está mediando aulas com o tema sobre a história antiga é possível trazer questões de gênero que eram vistas naquela época.Porém, dependerá deste educador o querer e o achar pertinente trazer a questão de gênero para o debate deste tema da aula.

Na Educação Infantil, o educador tem o propósito de cuidar e educar a criança. Nessa perspectiva a questão de gênero é importante de ser discutida, no entanto, alguns profissionais da área se veem "perdidos" em como abordar este tema com crianças, pois as mesmas já têm concepções sobre gênero que trazem de casa. "As manifestações da sexualidade afloram em todas as faixas etárias. Ignorar, ocultar ou reprimir são respostas habituais dadas por profissionais da escola, baseados na ideia de que a sexualidade é assunto para ser lidado apenas pela família” (PCN, 1997, p.291). É nesse sentido que a discussão de gênero deve ser debatida na escola, pois falar e ensinar sobre a sexualidade não é papel apenas da família, é papel da escola também, onde o educador deve mediar as questões de gênero que aparecem na escola, e deixar claro para as crianças que se um menino quiser usar uma camiseta rosa, ele pode usar uma camiseta rosa, e isso não fará com que o mesmo deixe de ser menino, e que, se uma menina quiser brincar de carrinho, a mesma pode brincar de carrinho e não deixará de ser menina.

No entanto, a discussão de gênero na escola para desconstruir o modelo imposto nos educandos se perdem nas próprias ações que a escola estabelece, pois na hora de fazer a fila para sair da sala é feita uma fila de meninos e outra fila de meninas, é proposto que cada educando frequente o banheiro específico definido por seu gênero, sendo que a própria escola pensando em descontruir esse paradigma poderia promover a ideia de banheiros que pudessem ser frequentados por ambos os gêneros. Por esses e muitos outros motivos 
A condução do processo educativo, como socialização da criança, desde a instituição familiar até a escola, está permeada de estereótipos de gênero, definindo - ou seja, autorizando ou interditando - determinados campos de conhecimento e de ação, como femininos ou masculinos. Assim, são sexuados os saberes, as áreas de conhecimento, os comportamentos e formas de expressão, a sexualidade, os desejos, etc. Entende-se, pois, que a maneira feminina de exercer o magistério, nas séries iniciais, favorece e valoriza o desempenho escolar das meninas (SILVA; BARROS; HALPERN; SILVA, 1999, p. 221).

A partir disso percebemos que o gênero está impregnado nos educandos, nas suas escolhas, nos seus saberes e nas suas reflexões. Mesmo que os educandos não sejam direcionados a se separarem por gêneros em âmbitos formais de escolarização e em âmbitos não formais de escolarização, seus subconscientes, culturas e costumes fazem com que os educandos automaticamente tomem atitudes relacionadas aos seus gêneros. Isso é fundamental para o entendimento do papel da escola na adoção de estereótipos de gênero, mas, sobretudo, no entendimento do modo como gênero se forma e se propaga.

No caso 1 dos exemplos de pesquisa em gênero do capítulo 2 do livro Gênero: uma perspectiva global (2015), Connel e Pearse analisam o estudo da etnógrafa estadunidense Barrie Thorne em seu livro sobre gênero e a vida escolar. Além dos padrões descritivos em modelos de gênero convencionais, Thorne observou não apenas os momentos do cotidiano escolar em que meninos e meninas eram separados, mas também nos momentos em que eram colocados juntos. Assim, a diferença de gênero em âmbito escolar é algo situacional, isto é, criado em algumas situações e ignorado e suprimido em outras.

Exemplo disso pode ser encontrado nos jogos do recreio, quando as crianças tipicamente se separam em grupos de meninas e meninos em diferentes partes do parque, e outras vezes engajam-se em atividades mistas sem qualquer ênfase na diferença. Os educadores também enfatizam e suavizam o gênero: organizam jogos educativos na classe com meninas competindo com meninos ou utilizam a técnica "giz e lousa", onde, de frente para a sala, o professor exige a atenção de todos os alunos para expor um conteúdo que todos devem aprender, sem distinção entre meninas e meninos. Sendo assim, as crianças e educandos

[...] não são passivamente "socializadas" em papéis de gênero. É claro que estão aprendendo a partir do mundo adulto ao redor delas: sobre que identidades estão disponíveis, performance e - infelizmente - ódio. Mas elas o fazem ativamente e segundo seus próprios termos. Acham o gênero interessante e, às vezes, empolgante. Transitam dentro e fora de agrupamentos baseados em gênero. Às vezes, sustentam e, às vezes movem-se entre fronteiras de gênero. Até brincam com e contra a dicotomia de gênero. $\mathrm{O}$ gênero é importante em seu mundo, mas como uma questão humana com a qual lidam e não como um quadro fixo que as reduz a marionetes (CONNEL; PEARSE, 2015, p. 57). 
Afirmar que a escola é uma propagadora de estereótipos de gênero sem inserir ressalvas no que tange ao modo como gênero é manipulado e acolhido, gera um tipo de reflexão bastante limitada que situa na socialização toda a fonte de nosso comportamento, retirando do indivíduo qualquer resquício de agência. O texto de Connel e Pearse (a partir da pesquisa de Barrie Thorne) é especialmente rico justamente porque permite pensar o gênero para além de algo imposto, mas também como algo acolhido. Considerando que os próprios educandos, que mesmo não sendo "obrigados" a se separarem por gênero para realizar determinadas ludicidades, executam essa separação entre meninos e meninas, observa-se não só uma repetição mas também, em alguma medida, um modo de se organizar.

\section{Limites e possibilidades do modelo da socialização de gênero}

"Arranjos de gênero são, ao mesmo tempo, fontes de prazer, reconhecimento e identidade, mas fontes de injustiça e dano" (CONNEL; PEARSE, 2015, p.43). Essa passagem de Connell e Pearse representa de maneira bastante satisfatória a verve da investigação que aqui nos propomos. Assim como os arranjos (muitos deles solidificados pela prática pedagógica) incidem no sentido de castrar certos anseios de crianças e adultos, eles, também, é preciso admitir, ensejam prazeres e realizações. A "descoberta" da socialização de gênero, seu caráter opressivo e desfigurante do ponto de vista identitário, mediante a imposição de estereótipos, é o vetor das análises feministas desde a chamada Segunda Onda do Feminismo (década de 70) e não só foi cooptado nas discussões entre gênero e educação como também por elas solidificados. Ninguém pretende questionar esses resultados, contudo, é preciso alertar que o caráter fortemente estrutural ocultou questões importantes que restaram invisibilizadas. Uma delas, diz respeito ao fato de que em alguns momentos ou muitos deles, os arranjos de gênero encontram alguma satisfação nos indivíduos. Vestir-se de rosa, brincar de boneca, usar sapato alto, maquiagem, brincar de carrinho ou fazer escolinha de futebol podem ser objeto de satisfação os quais ensejam a adesão a essas práticas. Aqui a questão da agência é fundamental: nos exemplos citados no item anterior, o foco não está propriamente no direcionamento de gênero inerente à organização da escola (cores, banheiro, fila), mas, sobretudo, no fato de que quando não existiam modelos impostos para o comportamento de meninas e meninos, as próprias crianças pareciam impor esse modelo. Ou seja, quando não se impõe, gênero é feito acontecer, e isso implica que as crianças não são passivamente socializadas, interagem e brincam de gênero em razão de verem nisso algo que as agrada.

Isso é particularmente importante quando pensamos que a maioria dos meninos e das meninas falham no que tange a atender aos ideais puros de gênero, ou seja, muitos meninos 
são altamente sensíveis, vaidosos e calados e muitas meninas são racionais, despojadas ou faladoras. Uma criança ou adulto "menina" dificilmente resplandece tudo o que é feminino assim como um "menino" não contém tudo o que é tido como masculino. Existe um intercâmbio e coexistência em que alguma ou algumas características femininas aparecem em meio a características masculinas em um menino e vice-versa. "A forma sobre como adquirimos o gênero precisa reconhecer ambas as contradições do desenvolvimento e o fato de que os aprendizes são ativos, não passivos" (CONNEL; PEARSE, 2015, p. 199). Isso denota que não há uma mera absorção dos modelos estruturados, mas certa negociação invisível difícil de definir de uma vez por todas ou homogeneizar em todos os indivíduos. Gênero é uma prática e enquanto um padrão de atividade não se esgota no modelo da socialização. Existem comprometimentos internos que podem ser prazerosos ou custar alto preço, mas que são executados também internamente e não só impostos. Isso não significa que essa estrutura não seja poderosa, mas que, embora possa explicar muito, não explica tudo. Ou seja, não exaure nossos questionamentos tampouco decodifica todas as nossas ações.

Abrir essa possibilidade de análise resulta fértil uma vez que alerta que, na constante fuga do determinismo biológico, a teoria de gênero corre o risco de se encerrar e reduzir ao determinismo social (o qual também é problemático). Abordagens estruturalistas e pósestruturalistas tendem a exagerar na docilidade de como nos submetemos aos padrões sociais de gênero, reduzindo, muitas das vezes os estereótipos a "jaulas de ferro", imperativos que não se pode burlar em nenhuma medida. Não somos meramente generificados, tampouco nossos corpos são telas em branco as quais a cultura pinta matizes masculinos e femininos. Temos alguma participação nisso. Mesmo que mínima e pouco consciente, abordar a agência é fundamental para o entendimento da propagação dos estereótipos de gênero.

A escola como instituição de vivência e desenvolvimento de indivíduos se constitui em foco e ponto de encontro de habitus socialmente estruturados, por um lado, e, agência, por outro. Com efeito, não se pode pensar o papel pedagógico e a própria organização escolar como um bloco agente que, por um lado, toca e é absorvido sem resistência e reflexão pelo educando, ou, por outro lado, como uma estrutura não reagente. Para cada ação escolar de formação de gênero, existe o acolhimento interno de cada educando, o qual é transpassado por sua cultura familiar e intersecções de classe e raça. Para cada resistência, existe certo rebote que move a própria estrutura que a escola pretende propagar. $\mathrm{O}$ que pretendemos trazer com isso, é que para cada ação visível, particularmente no que tange aos estereótipos de gênero, existe uma ação invisível de adesão, resistência ou mudança que se mescla com ela. A mudança pode se dar na vida de cada um, como resistência ou adesão ao que é apresentado 
como o comportamento adequado, mas também, na hipótese de resistência ou questionamento, existe, embora em menor grau, uma alteração no modo como essas questões são apresentadas e trabalhadas no contexto escolar. Essas questões são fundamentais quer no sentido de não apresentar os indivíduos como meros receptáculos que são formados pelo ambiente escolar sem colocar nada de si nessa formação, seja da sua vivência seja de sua agência, quer no sentido de apontar que as instituições (embora em ritmo mais moroso) também se alteram em vista do que recebem como retorno dos indivíduos.

Dissertar acerca das relações entre gênero e educação ou das alocações de gênero inerentes à organização educacional e práxis pedagógica se constitui em uma tarefa árida quer em vista do conteúdo mobilizado (por ser um campo tão fértil, sempre resta algo a ser analisado ou dito - uma abordagem mais próxima do ideal dificilmente caberia em um artigo) quer em vista da profundidade inerente à gênero e educação enquanto teorias independentes, as quais se tornam ainda mais complexas quando avaliadas em conjunto. Perceber, entender e definir as relações entre gênero e educação ocupa um espaço epistêmico inteseccional que implica também o modo, local e situação em que cada um vivencia o mundo. Assim, esse texto, seja pela complexidade da temática que aborda, seja pelo caráter parcial da produção de conhecimento a partir da localização do sujeito epistêmico, é por si mesmo inconcluso, ou ainda, pede que cada leitor busque suas conclusões. Trata-se de uma investigação teóricoexploratória que guarda como intento muito mais problematizar do que oferecer bases sólidas de conclusão.

\section{Referências}

BEAUVOIR, Simone de. O Segundo Sexo. 2.ed. - Rio de Janeiro : Nova Fronteira, 2009.

BRASIL. Diretrizes Curriculares Nacionais Gerais da Educação Básica / Ministério da Educação. Secretaria de Educação Básica. Diretoria de Currículos e Educação Integral. Brasília: MEC, SEB, DICEI, 2013.

BRASIL.Parâmetros Curriculares Nacionais: Orientação Sexual.Brasília: MEC/SEF, 1997. Disponível em: https://cptstatic.s3.amazonaws.com/pdf/cpt/pcn/volume-10-6-temastransversais-orientacao-sexual.pdfAcessado em: 17/11/2018.

BRASIL.Parâmetros Curriculares Nacionais: apresentação dos temas transversais, ética. Brasília: MEC/SEF, $1997 . \quad$ Disponível em: http://portal.mec.gov.br/seb/arquivos/pdf/livro081.pdf Acessado em: 17/11/2018.

CONNELL, Raewyn; PEARSE, Rebecca. Gênero: uma perspectiva global. São Paulo: InVerso, 2015. 
LOURO, Guacira Lopes. Pedagogias das Sexualidades. In: LOURO, Guacira Lopes (Org.). O Corpo Educado. Belo Horizonte: Autêntica, 2000.

MALAGUZZI, L. (1999). História, ideia e filosofia básica. In: Carolyn Edwards, Lella Gandini e George Forman. As cem linguagens da criança: a abordagem de Reggio Emilia na educação da primeira infância, 59-104. Porto Alegre: Artmed.

NICHOLSON, Linda. Interpretando o gênero. Revista Estudos Feministas, vol. 8, $\mathrm{n}^{\mathrm{o}} 2$, Florianópolis, 2000, pp.9-41

SAFFIOTI, Heleieth I. B. O Poder do Macho. São Paulo: Moderna, 1987. (Coleção Polêmica).

SCOTT, Joan. (1991), Gênero: uma categoria útil de análise histórica. (Tradução de Christine Rufino Dabat e Maria Betânia Ávila). Recife, SOS Corpo. (sd)

SILVA, Cármen A. Duarte da; BARROS, Fernando; HALPERN, Sílvia C.; SILVA, Luciana A. Duarte da. Meninas bem-comportadas, boas alunas; meninos inteligentes, indisciplinados. Cad. Pesqui., São Paulo, n. 107, p. 207-225, July 1999. 